\title{
Preparation of anastrozole loaded PEG-PLA nanoparticles: evaluation of apoptotic response of breast cancer cell lines
}

This article was published in the following Dove Press journal: International Journal of Nanomedicine

\author{
Yusra A Alyafee ${ }^{1,2}$ \\ Manal Alaamery' \\ Shahad Bawazeer \\ Mansour S Almutairi' \\ Badr Alghamdi' \\ Nawaf Alomran' \\ Atia Sheereen' \\ Maha Daghestani \\ Salam Massadeh ${ }^{1,3}$ \\ 'Developmental Medicine Department, \\ King Abdullah International Medical \\ Research Center, King Saud Bin \\ Abdulaziz University for Health \\ Sciences, King AbdulAziz Medical City, \\ Ministry of National Guard Health \\ Affairs, Riyadh, Kingdom of Saudi \\ Arabia; ${ }^{2}$ Department of Zoology/ \\ College of Science/King Saud \\ University (KSU), Riyadh, Kingdom of \\ Saudi Arabia; ${ }^{3}$ College of Pharmacy, \\ King Saud bin Abdulaziz University \\ for Health Sciences, King Abdullah \\ International Medical Research Center, \\ King Abdulaziz Medical City, Ministry \\ of National Guard, Health Affairs, \\ Riyadh, Kingdom of Saudi Arabia
}

Correspondence: Salam Massadeh Developmental Medicine Department, King Abdullah International Medical Research Center (KAIMRC), Ministry of National Guard - Health Affairs, PO Box 22490, Riyadh II426,

Kingdom of Saudi Arabia

Tel +966 56 I03 658I

Email salam_masadeh@yahoo.com
Purpose: Anastrozole (ANS) is an aromatase inhibitor that is widely used as a treatment for breast cancer in postmenopausal women. Despite the wide use of ANS, it is associated with serious side effects due to uncontrolled delivery. In addition, ANS exhibits low solubility and short plasma half-life. Nanotechnology-based drug delivery has the potential to enhance the efficacy of drugs and overcome undesirable side effects. In this study, we aimed to prepare novel ANS-loaded PLA-PEG-PLA nanoparticles (ANS-NPs) and to compare the apoptotic response of MCF-7 cell line to both ANS and ANS-loaded NPs.

Method: ANS-NPs were synthesized using double emulsion method and characterized using different methods. The apoptotic response was evaluated by assessing cell viability, morphology, and studying changes in the expression of MAPK3, MCL1, and $c-M Y C$ apoptotic genes in MCF-7 cell lines.

Results: ANS was successfully encapsulated within PLA-PEG-PLA, forming monodisperse therapeutic NPs with an encapsulation efficiency of $67 \%$, particle size of $186 \pm 27.13$, and a polydispersity index of $0.26 \pm 0.11$ with a sustained release profile extended over 144 hours. In addition, results for cell viability and for gene expression represent a similar apoptotic response between the free ANS and ANS-NPs.

Conclusion: The synthesized ANS-NPs showed a similar therapeutic effect as the free ANS, which provides a rationale to pursue pre-clinical evaluation of ANS-NPs on animal models.

Keywords: anastrozole, PLA-PEG-PLA, anti-apoptosis, gene expression, therapeutic nanoparticles

\section{Introduction}

Carcinogenesis is fundamentally an outcome of changes in the genetic code or gene expression. The altered gene can be an oncogene, a tumor suppressor gene or a mismatch repair gene. Alterations in gene signaling may lead to continuous cell proliferation signaling or resistance to cell death. ${ }^{1}$ This unique expression profile of apoptosis-associated genes, including pro- and anti-apoptotic signaling proteins, in cancer cells compared to normal cells provides therapeutic targets for cancer diagnosis and therapy. ${ }^{2}$ For example, in MCF-7 breast cancer cells, 324 genes associated with apoptosis and cell growth have been studied, and the results showed that only several anti- and pro-apoptotic genes are down-regulated or not expressed and that the upregulated genes include anti-apoptotic genes, such as $M C L-1$, suggesting a major role for epigenetic mechanisms in breast cancer development and providing a target mechanism for personalized medicine. ${ }^{3}$ 
Anastrozole(ANS) (2,2-[5-(1H-1,2,4-triazol-1-ylmethyl)1.3-phenylene]), which is commercially available as Arimidex, is an aromatase inhibitor (AI) that is used as an anticancer medication for the adjuvant or first-line treatment of estrogen receptor-positive breast cancer in postmenopausal women. ANS acts by reversibly binding to aromatase and inhibiting its actions, thus inhibiting the conversion of androgens to estrogen. ${ }^{4}$ Depriving hormone-dependent breast cancer from estrogens is a major treatment strategy, thus AIs have a vital role in the treatment of breast cancer. ${ }^{5}$ The commonly prescribed dosage of ANS is a $1 \mathrm{mg}$ tablet per day for a treatment period lasting approximately 2.5 years. ${ }^{6}$ However, ANS exhibits low solubility in water and is rapidly removed from the blood stream, thus resulting in a short halflife in the plasma (41-48 hours) and irregular drug uptake. ${ }^{6}$ Moreover, ANS is associated with many adverse effects including gastrointestinal disturbances, vaginal bleeding, thrombocytosis, and osteoporosis. ${ }^{7}$

Nanotechnology is often used to overcome the disadvantages of active ingredients. Specifically, nano-vehicles provide an established approach to protecting the drug from clearance and increasing site-specific drug delivery by coupling the drug to targeted carrier particles, such as nanospheres, nanocapsules, and micelles. ${ }^{8}$ Moreover, entrapping hydrophobic compounds inside a nano-vehicle can dramatically increase solubility, delivery efficiency, and, ultimately, efficacy. ${ }^{9}$ With regard to ANS, the first publication describing encapsulation of this drug was by Zidan et $\mathrm{al}^{10}$ using biodegradable PLGA-based microparticles. Most of the reported studies have focused on the use of dendrimers, ${ }^{11}$ chitosan, ${ }^{7}$ and PLGA nanoparticles (NPs). ${ }^{12}$ PLA-PEG-PLA NPs were chosen in this study as they are non-toxic and biodegradable. PLA-PEG-PLA NPs are synthesized from PEG, which is characterized by resistance to immunological recognition, in combination with PLA, which can be completely broken down without any toxicity. In addition, it has been previously approved by the US Food and Drug Administration for many applications. ${ }^{13,14}$

In this study, we report for the first time the synthesis of ANS-loaded PLA-PEG-PLA NPs (ANS-NPs) using the double emulsion technique to efficiently deliver ANS to target cells. The physical properties of the ANS-NPs and the therapeutic efficiency of the particles in MCF-7 breast cancer cells were studied. This work has shown the expression of several apoptosis-associated genes like; $M C l-1, c-M Y C$, and $M A P K 3$ in the presence of ANS-NPs. The promising results of this study can also open the doors for other in vivo work to show the effectiveness of ANS-loaded NPs.

\section{Materials and methods Materials}

Polylactide-block-poly (ethylene glycol)-block-polylactide triblock (PLA: average $\mathrm{Mn}=1,500$; PEG average $\mathrm{Mn}=900$ ), ANS (MW =293.37, purity, $\geq 98 \%$ [HPLC]), chloroform, poly (vinyl alcohol) (PVA: Mw $=89,000-98,000 ; 99 \%$ hydrolyzed), InP/ZnS quantum dots (QDs) (776777) and DMSO were obtained from Sigma-Aldrich Co., St Louis, MO, USA and were used as received. DMEM, PBS, and Celldiss were obtained from UFC (Riyadh, Saudi Arabia). FBS, penicillinstreptomycin and L-glutamine were purchased from Gibco (Thermo Fisher Scientific, Waltham, MA, USA). The CellTiter $96{ }^{\circledR}$ Aqueous One Solution Cell Proliferation Assay (3-(4,5-dimethylthiazol-2-yl)-5-(3-carboxymethoxyphenyl)2-(4-sulfophenyl)-2H-tetrazolium [MTS]) kit was purchased from Promega Corporation, (Fitchburg, WI, USA). The PureLink ${ }^{\circledR}$ RNA Mini Kit was purchased from Ambion-Life Technologies (Thermo Fisher Scientific). The High-Capacity cDNA Reverse Transcription Kit and Taqman ${ }^{\circledR}$ gene expression master mix were purchased from Applied Biosystems ${ }^{\mathrm{TM}}$ (Thermo Fisher Scientific). Pre-designed primers for MAPK3 (Hs00385075_m1), MCL-1 (Hs01050896_m1), c-MYC (Hs00153408_m1), and GAPDH (Hs02786624_g1) were obtained from Applied Biosystems.

\section{Preparation of 3\% PVA}

To prepare $3 \%$ PVA, $3 \mathrm{~g}$ of PVA was weighed and dissolved in $100 \mathrm{~mL}$ of distilled water. The weighed amount was added gradually to cold water while stirring. After adding the full amount, the solution was heated to $140^{\circ} \mathrm{C}$ for 2 hours while the container was covered with aluminum foil to evenly distribute the heat. After 2 hours, a clear solution was obtained.

\section{Synthesis of empty, ANS drug-loaded PLA-PEG-PLA and/InP:ZnS QD NPs}

The NPs were prepared using the double emulsion method. ${ }^{15}$ First, $15 \mathrm{mg}$ of PEG-PLA was dissolved in $1 \mathrm{~mL}$ of chloroform. Empty NPs were made with DMSO $(200 \mu \mathrm{L})$, whereas drug-loaded NPs were made with a $200 \mu \mathrm{L}(1 \mathrm{mg} / \mathrm{mL})$ volume of ANS dissolved in $1.0 \mathrm{~mL}$ of DMSO. As for the QD encapsulated NPs (QD/ANS-NPs), they were synthesized using $100 \mu \mathrm{L}$ of commercially available InP:ZnS QD solution and $100 \mu \mathrm{L}$ of DMSO. The DMSO, ANS + DMSO or QD + DMSO was emulsified by ultrasonication using a $2 \mathrm{~mm}$ probe (VCX 130 ultrasonic processor; Sonics, Newtown, CT, USA) (30 s, 100\% power) in the PEG-PLA solution. The first emulsion was generated by adding $2 \mathrm{~mL}$ 
of $3 \%$ PVA followed by emulsification in the polymer/DMSO or polymer/ANS + DMSO solution via ultrasonication using a $2 \mathrm{~mm}$ probe ( $30 \mathrm{~s}, 100 \%$ power). The resulting emulsion was then diluted by adding $20 \mathrm{~mL}$ of $0.3 \%$ PVA solution, after which the white emulsion was centrifuged for 1 hour at $16,000 \mathrm{rpm}$; for the drug-loaded NPs, this step was repeated three times to remove any excess drug.

\section{Characterization of empty and drug- loaded NPs}

Particle size analysis

The particle size distribution (mean diameter and polydispersity index [PDI]) of NPs was determined using a Brookhaven ZetaPALS analyzer (Brookhaven, New York, NY, USA). Each NP preparation was analyzed five times per NP sample. The zeta potential was determined by phase analysis light scattering using the ZetaPALS at $658 \mathrm{~nm}$ with a scattering angle of $90^{\circ}$ at $25^{\circ} \mathrm{C}$.

\section{Transmission electron microscopy (TEM)}

To observe the morphology and size distribution of the ANS-NPs, TEM was performed using a JEOL transmission electron microscope (model JEM-1400 electron microscope; JEOL, Tokyo, Japan) operating at an acceleration voltage of $120 \mathrm{kV}$. A drop of the sample $(1 \mathrm{mg} / \mathrm{mL})$ solution was placed on a 400 mesh carbon-coated copper grid. The samples were air dried at room temperature before measurement.

\section{Scanning electron microscopy (SEM)}

The scanning electron microscope FEI Nova NanSEM 450 was used to investigate the chemical composition and surface morphology of the ANS-NPs. A drop of the NP solution was placed on an SEM stub with carbon conductive tape stuck on its surface. The solution was air dried and then the sample was coated with a thin conductive layer of gold using a Quorum Q300 D sputter coater with a sputter time of $20 \mathrm{~s}$ and $20 \mathrm{~mA}$ sputter current. An accelerating potential between $15-18 \mathrm{kV}$ was used for SEM analyses.

\section{Encapsulation efficiency (EE) and loading capacity (LC)}

The EE and drug-LC were determined by calculating the ratio between the encapsulated drug (ANS) and the total amount of added drug. This was achieved by dissolving the loaded NPs in DMSO and measuring the absorbance of ANS-NPs at a $\lambda \max$ of $360 \mathrm{~nm}$ using a SpectraMax Plus 384 UV spectrophotometer (Molecular Devices LLC, Sunnyvale, CA, USA) to determine the amount of encapsulated drug in each batch.
The EE of the NPs was then calculated using the following formula:

$$
\begin{gathered}
\mathrm{EE}=\frac{\text { Encapsulated drug }}{\text { Amount of drug used }} \times 100 \\
\% \mathrm{LC}=\frac{\text { Entrapped drug }}{\text { NPs weight }} \times 100
\end{gathered}
$$

\section{Determination of in vitro release of loaded NPs}

Three different batches of ANS-NPs were dispersed by a bath sonicator (Branson 3800, Emerson, CT, USA) for $20 \mathrm{~min}$ with the release media $(1.0 \mathrm{~mL}$ of phosphate buffer, $\mathrm{pH}=7.4)$. An amount equivalent to $1 \mathrm{mg}$ of the ANS-NPs in $1.0 \mathrm{~mL}$ of PBS ( $\mathrm{pH}=7.4$ ) was placed inside sealed cellulose dialysis tubing (Carolina, Burlington, NC, USA) with a cutoff of 12,000-14,000 Da. Then dialysis tubing was placed in a screw-cap bottle with $19.0 \mathrm{~mL}$ release media and kept in a shaking water bath (GFL 1083; GFL, Burgwedel, Germany) at $37^{\circ} \mathrm{C}$ and medium speed. At different time intervals, aliquots of $2.0 \mathrm{~mL}$ were withdrawn and immediately replaced with the same volume of fresh release media. The amounts of drug released were assessed at a $\lambda \max$ of $360 \mathrm{~nm}$ using a SpectraMax Plus384 UV spectrophotometer (Molecular Devices LLC) following the method prescribed. ${ }^{16}$

\section{Cell culture conditions}

The MCF-7 cell line, originally obtained from the American Type Culture Collection (ATCC; Manassas, VA, USA), was kindly provided by the core facility at the King Abdullah International Medical Research Center. The MCF-7 cells were maintained as an attached monolayer culture in commercially available DMEM supplemented with $10 \%(\mathrm{v} / \mathrm{v})$ FBS, $2 \mathrm{mM}$ 1-glutamine, and $100 \mathrm{U} / \mathrm{mL}$ and $100 \mu \mathrm{g} / \mathrm{mL}$ penicillin and streptomycin.

The cells were grown on either 25 or $75 \mathrm{~cm}^{2}$ attachedtype, filter-cap culture flasks (NunClon, Sigma Aldrich). The cells were incubated at $37^{\circ} \mathrm{C}$ in a $90 \%$ humidified atmosphere containing $5 \% \mathrm{CO}_{2}$.

\section{Sample preparation}

The stock solutions of free ANS and ANS-NPs were prepared in DMSO as $1 \mathrm{mg} / \mathrm{mL}$ and stored at $4^{\circ} \mathrm{C}$. At the time of the in vitro studies, stock solutions were diluted in DMEM supplemented with $10 \%$ FBS prior to treatment of the cells. Cells were treated with 15, 20, 40, and $80 \mathrm{nM}$ ANS or ANSNPs, based on the IC50 of ANS, which is $15 \mathrm{nM}$ according to Duke et al. ${ }^{17}$ 


\section{Cell proliferation assay}

The antiproliferative effect of ANS on MCF-7 cells was evaluated using the CellTiter $96^{\circledR}$ Aqueous One Solution Cell Proliferation Assay (MTS) according to the manufacturer's instructions. This assay is a colorimetric test to determine the number of viable cells. It contains MTS combined with the electron coupling reagent phenazine methosulfate.

The cells were seeded onto 96-well plates (Greiner Diagnostic $\mathrm{GmbH}$, Bahlingen, Germany) at a concentration of $10 \times 10^{3}$ cells/well and incubated for at least 24 hours. Then, different dilutions $(15,20,40$, and $80 \mathrm{nM})$ of both free ANS and ANS-NPs were added $(100 \mu \mathrm{L} /$ well). Each concentration was added in triplicate, and every plate contained a set of cells in growth medium alone as a control. The cells were then incubated at $37^{\circ} \mathrm{C}$ for 72 hours.

After incubation, $20 \mu \mathrm{L}$ of the MTS dye solution was added to each well. The plates were incubated at $37^{\circ} \mathrm{C}$ for 4 hours. Optical density (OD) at the $490 \mathrm{~nm}$ wavelength was recorded using a 96-well plate reader (SpectraMax Plus 384 Microplate Spectrophotometer). The cell viability \% was calculated using the following formula:

$$
\text { Cell viability } \%=\frac{\text { OD of the treated }}{\text { OD of the control }} \times 100 \text {. }
$$

\section{Cell morphological changes}

To determine morphological changes of the MCF-7 cells following treatment with ANS, empty NPs and ANS-NPs, the MCF- 7 cells were seeded at a density of $5 \times 10^{4}$ cells per well in a 6-well plate and cultured at $37^{\circ} \mathrm{C}$ for 12 hours, then treated with ANS, empty NPs and ANS-NPs (15, 20, 40 , and $80 \mathrm{nM}$ ) for 72 hours. The cells were then observed and captured under microscope (Nikon Eclipse TiS coupled with NIS-Elements imaging software; Nikon Corporation, Tokyo, Japan).

\section{In vitro cellular uptake and fluorescence imaging}

To evaluate the cellular uptake, we used the InP: $\mathrm{ZnS}$ QD-NPs. MCF-7 cells were then cultured in 8-chamber polystyrene vessel tissue culture treated glasses at a density of $5^{*} 10^{4}$ cells/chamber, at $37^{\circ} \mathrm{C}$, for 12 hours in an atmosphere containing $5 \% \mathrm{CO}_{2}$ to allow cells' attachment. Subsequently, the medium was aspirated from each chamber and replaced with medium containing InP:ZnS QD-NPs at concentrations of $1,000 \mathrm{mg} / \mathrm{mL}$. Chambers were then incubated at $37^{\circ} \mathrm{C}$ for 4 hours in an atmosphere containing $5 \% \mathrm{CO}_{2}$. The cellular uptake assay was stopped by aspirating the test samples, removing the chamber, and washing the cell monolayers with ice-cold PBS three times. Examination was done using confocal microscope (LSM-780, Carl Zeiss Meditec AG, Jena, Germany).

\section{RNA isolation}

RNA was isolated using a PureLink ${ }^{\circledR}$ RNA Mini Kit following the manufacturer's instructions. The purity of the isolated RNA was determined by measuring the ratio of the OD of the samples at 260 and $280 \mathrm{~nm}$ using a NanoDrop ${ }^{\text {TM }} 8000$ spectrophotometer. The $\mathrm{OD}_{260} / \mathrm{OD}_{280}$ ratio ranged from 1.9 to 2.2 for all samples.

\section{cDNA synthesis}

cDNA strands were synthesized using a High-Capacity cDNA Reverse Transcription Kit (Applied Biosystems ${ }^{\mathrm{TM}}$ ) according to the manufacturer's instructions; aliquots containing $1 \mu \mathrm{g}$ of total RNA were used from each sample.

\section{Gene expression profiling and data analysis}

Real-time PCR for the apoptosis-associated genes MAPK3, $M C L 1$, and $c-M Y C$ was performed after incubating the cells with 20,40, and $80 \mathrm{nM}$ ANS or ANS-NPs. An Applied Biosystems 7900HT Fast Real-Time PCR System and TaqMan ${ }^{\circledR}$ Gene Expression master mix (Thermo Fisher Scientific) were used, and then, gene expression was manually quantitated using the delta-delta $\mathrm{CT}\left(\Delta \Delta^{\mathrm{CT}}\right)$ method. Changes in gene expression were illustrated as a fold increase or decrease. The data were normalized to the housekeeping gene GAPDH.

\section{Results}

\section{Synthesis of ANS loaded PLA-PEG-PLA NPs and particle size analysis}

In this study, we aimed to synthesize biocompatible PLAPEG-PLA NPs that are capable of encapsulating ANS as potential breast cancer therapy. Biodegradable polymers have the advantage of the sustained release of some active ingredients. Furthermore, the synthesis of the ANS-NP was carried out using the double emulsion method. The PLAPEG-PLA polymer was dissolved in the oil phase while the ANS was suspended in DMSO. Using ultrasonication, the first unstable emulsion formed, subsequently, the emulsion was stabilized using PVA. The ANS-NP was washed three times by repeated precipitation and re-suspension in water, to remove all the excess impurities.

The synthesized particles were characterized by dynamic light scattering using ZetaPALS, ANS-NPs synthesized were within the size range of $186 \pm 27.13 \mathrm{~nm}$; which is slightly larger than the void polymer NPs with a particle size of 
Table I Median particle size and potential of free, and ANS loaded nanoparticles

\begin{tabular}{lllll}
\hline Formulation & $\begin{array}{l}\text { Particle } \\
\text { size }(\mathbf{n m})\end{array}$ & $\begin{array}{l}\text { Polydispersity } \\
\text { index }\end{array}$ & $\begin{array}{l}\text { Zeta } \\
\text { potential } \\
(\mathbf{m V})\end{array}$ & $\begin{array}{l}\text { Mobility } \\
(\mu / \mathrm{s})(\mathrm{V} / \mathrm{cm})\end{array}$ \\
\hline $\begin{array}{l}\text { (PLA-PEG- } \\
\text { PLA) NPs }\end{array}$ & $18 \mathrm{I} \pm 30.19$ & $0.26 \pm 0.12$ & $0.08 \pm 0.42$ & $0.01 \pm 0.03$ \\
ANS-loaded & $\mathrm{I} 86 \pm 27.13$ & $0.26 \pm 0.1 \mathrm{I}$ & $0.48 \pm 3.8 \mathrm{I}$ & $0.04 \pm 0.01$ \\
NPs & & & & \\
\hline
\end{tabular}

Abbreviations: ANS, anastrozole; NPs, nanoparticles.

$181 \pm 30.19 \mathrm{~nm}$ (Table 1). Similarly, the PDI was found to be $0.26 \pm 0.11$ which shows a relatively homogeneous size distribution. Further, the zeta potential and electrophoretic mobility of the ANS-NP was approximately $0.48 \pm 3.81$ and $0.04 \pm 0.01$ respectively (Table 1 ), which makes them almost neutral in charge and able to be dispersed in a media of physiological pH. The optimal size of an NP is between 10-200 nm. ${ }^{18}$ As a result, this work provides a successful method to synthesize and optimize the size of NPs.

\section{ANS EE and LC}

Multiple factors can influence drug entrapment efficiency varying between the composition of the polymer to the type of drug to be used and the method of preparation. In this study, drug EE was determined. EE of ANS-NP was found to be $67 \%$ when the concentration of the drug used was $1 \mathrm{mg} / \mathrm{mL}$. The LC of the NPs was $1.65 \%$. The percentage yield was calculated to be $54 \%$.
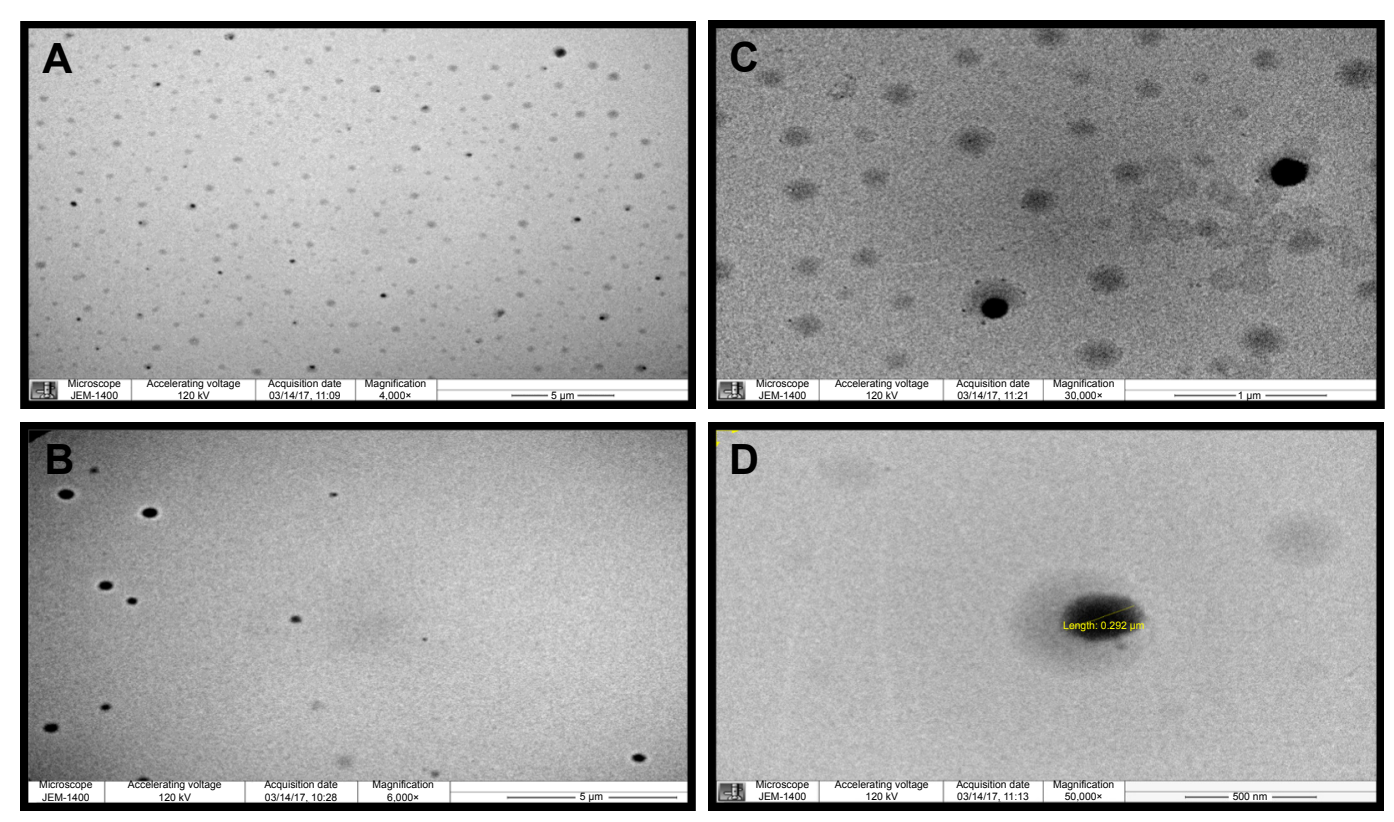

Figure I TEM micrograph of PEG-PLA ANS-NPs.

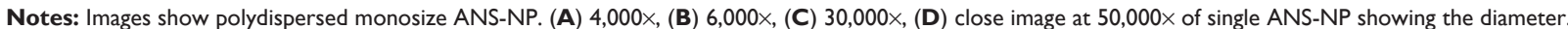
Abbreviations: TEM, transmission electron microscopy; ANS, anastrozole; NPs, nanoparticles.

\section{TEM and SEM}

TEM was used to observe the morphology and size distribution of the ANS-NPs (Figure 1). TEM observation of the ANS-NPs showed that the NPs were spherical and welldispersed as discrete particles. The particle size was also measured by TEM and it showed similarity to the dynamic light scattering readings. SEM micrograph (Figure 2) showed that the particles were aggregated in spherical shape and merged together in one big aggregate and the measurements were in the same range of what the TEM has shown.

\section{In vitro drug release studies}

The in vitro drug release study was used to determine the ability of the PLA-PEG-PLA NP to release ANS. The release profile of three different batches of ANS-NPs was measured at different time intervals over a period of 144 hours. As illustrated in Figure 3, the release profile of the three batches was quite similar and exhibited sustained drug release over 144 hours.

\section{Cell proliferation assay}

To investigate the antiproliferative effect of ANS-NPs in vitro, MCF-7 cells were treated with different concentrations, ranging from 15 to $80 \mathrm{nM}$, of ANS and ANS-NPs for 72 hours, and the cell viability was then measured using MTS assay.

As shown in Figure 4, empty PEG-PLA NPs showed no significant cytotoxicity against MCF-7 cells (inhibition $<10 \%$ ). 

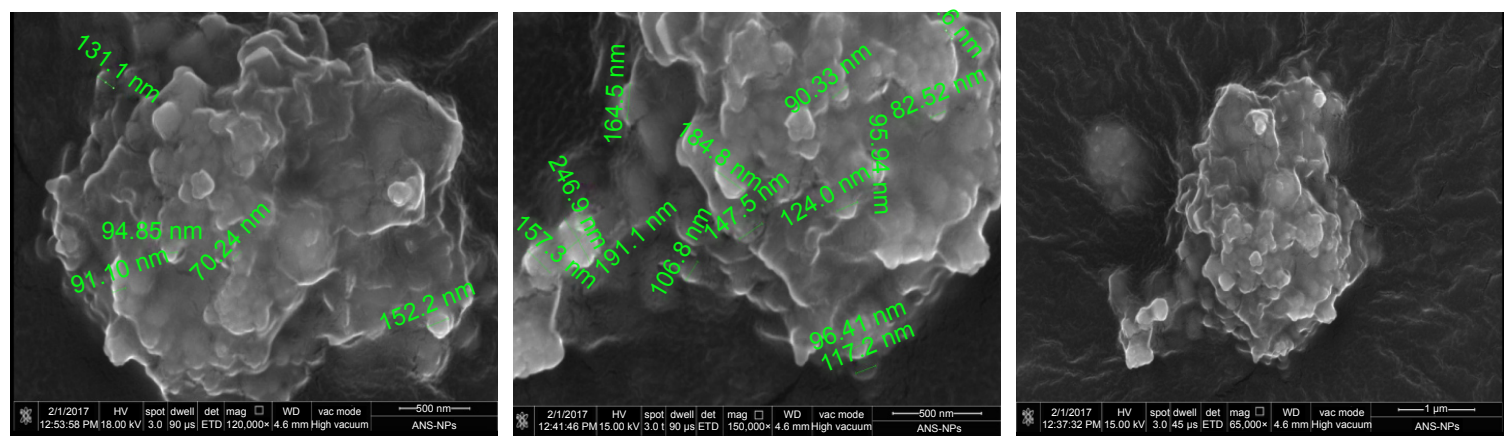

Figure 2 SEM micrograph of PEG-PLA ANS-NPs showing the NPs in the aggregate form Abbreviations: SEM, scanning electron microscopy; ANS, anastrozole; NPs, nanoparticles.

By contrast, ANS-NPs inhibited the growth of MCF-7 cells after incubation for 72 hours. ANS-NPs exhibited a similar toxic effect as the free drug, suggesting the successful uptake and delivery of the NPs to the cells.

\section{Cell morphological changes}

To evaluate the morphological changes of the MCF-7 cells in response to the ANS-NPs, cells were treated with different concentrations, ranging from 15 to $80 \mathrm{nM}$ of ANS, empty NPs and ANS-NPs for 72 hours, and the cells were then observed under the microscope.

As shown in the representative photos in Figure 5, empty NPs showed no significant cytotoxicity against MCF-7 cells. On the other hand, ANS-NPs inhibited the growth of MCF-7 cells after incubation for 72 hours exhibiting a similar toxic effect as the free drug, confirming the results obtained from the cytotoxicity assay.

In vitro cellular uptake and fluorescence imaging To evaluate the cellular uptake, fluorescent InP:ZnS QD/ ANS-NPs treatment was used on MCF-7 breast cancer cell

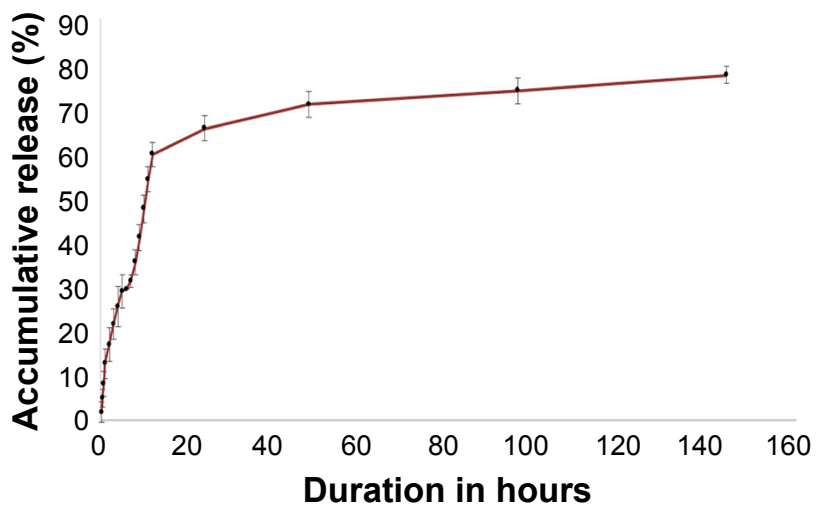

Figure 3 Cumulative drug release of ANS-loaded PLA-PEG-PLA NPs over a period of 144 hours.

Note: Error bars represent standard error of the mean for three different batches. Abbreviations: ANS, anastrozole; NPs, nanoparticles. line. Figure 6A shows the optical and fluorescence imaging of MCF-7 cells before starting the treatment. After treatment with InP:ZnS QD/ANS-NPs and incubation for 4 hours, cells exhibited fluorescent emission from the cell plasma area, suggesting successful cellular uptake (Figure 6).

\section{Gene expression profiling and data analysis}

MCF-7 breast cancer cell lines were treated with ANS and ANS-NPs in three different concentrations for 96 hours. The control for this experiment was untreated MCF-7 cell lines. Real-time results showed a similar expression behavior of $c-M Y C, M A P K 3$, and $M C L-1$ in both MCF-7 cell lines treated with free ANS and ANS-NP (Figure 7).

\section{Discussion}

Breast cancer is one of the most common cancers and is the main cause of death among women worldwide. ${ }^{19}$

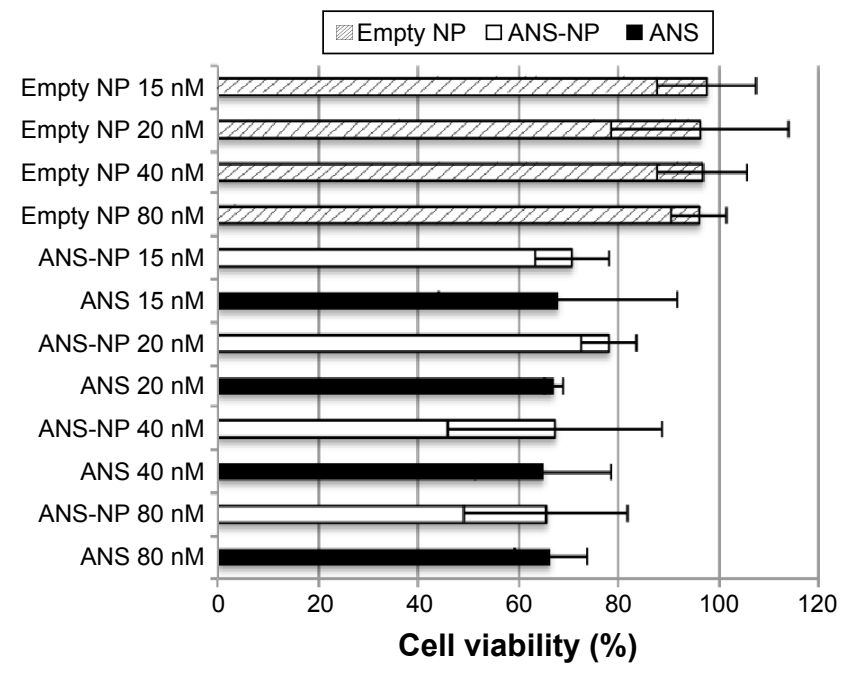

Figure 4 Cytotoxicity of ANS-NPs toward MCF-7 cells after incubation for 72 hours $(n=3)$.

Notes: Results show a proximal toxic behavior between the ANS and ANS-NP with no obvious effect of the increased concentration of the treatments. Moreover, the void NPs show no toxicity $(<10 \%)$ toward the cells even with increased concentration used for the NPs. Error bars represent standard error of the mean $(n=3)$. Abbreviations: ANS, anastrozole; NP, nanoparticle. 

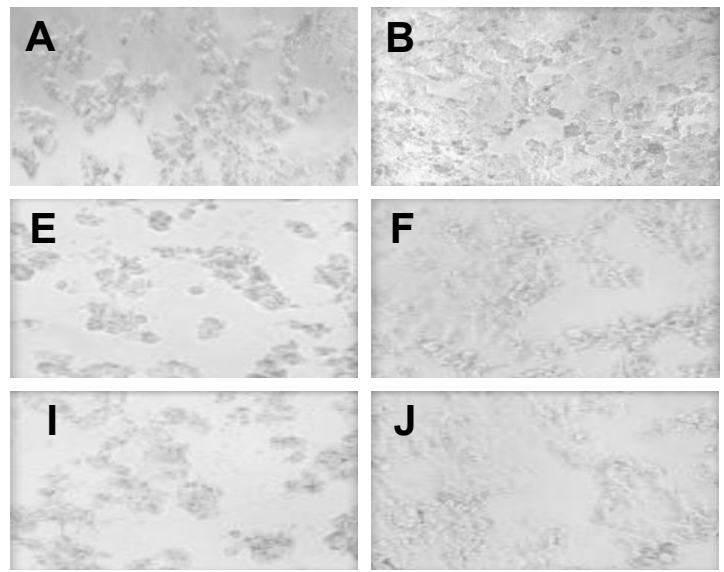
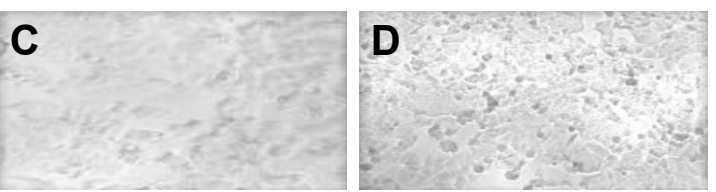

H
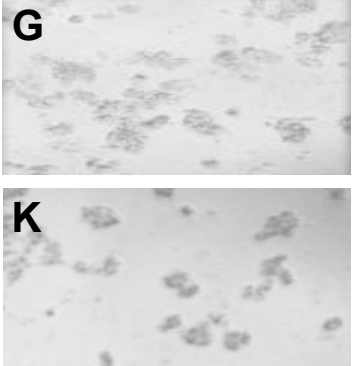

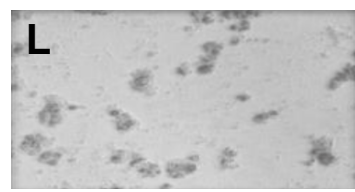

Figure 5 Representative photos show MCF-7 cells after incubation for 72 hours (magnification power 20x).

Notes: (A) Control of untreated cells. (B-D) Represent cells treated with I5, 40, $80 \mathrm{nM}$ of empty NPs respectively. (E, G, I, K) Show cells treated with I5, 20, 40, $80 \mathrm{nM}$ of free ANS respectively, while (F, H, J, L) demonstrate photos of cells treated with 15, 20, 40, $80 \mathrm{nM}$ of ANS-NPs respectively.

Abbreviations: ANS, anastrozole; NPs, nanoparticles.

Approximately $70 \%$ of all breast cancers are estrogen receptor $\alpha$ positive and are thus treated with treatments such as anti-estrogens or AIs, which suppress the estrogen-mediated pathways. ${ }^{20}$ Hormonal therapy with AIs is now the standard treatment for postmenopausal women with estrogen receptor $\alpha$ positive breast cancer, both as an adjuvant therapy and in the treatment of advanced disease. AIs block estrogen production by inhibiting or inactivating aromatase to ultimately inhibit the growth of breast tumors. ${ }^{21}$ The AI ANS blocks the production of estrogen, thus exerting antiproliferative effects on tumor cells. However, ANS is characterized by its low solubility in water and its rapid clearance from the blood stream, which may limit the efficiency of the drug. ANS is also associated with uncontrolled delivery, which results in adverse effects. In this study, we described the synthesis of PLA-PEG-PLA NPs encapsulating ANS using the double emulsion method. The biodegradable polymers enable the sustained release of certain active ingredients. The triblock polymer that was used for NP synthesis is an amphiphilic polymer suitable for the encapsulation of water-insoluble compounds. ${ }^{22}$
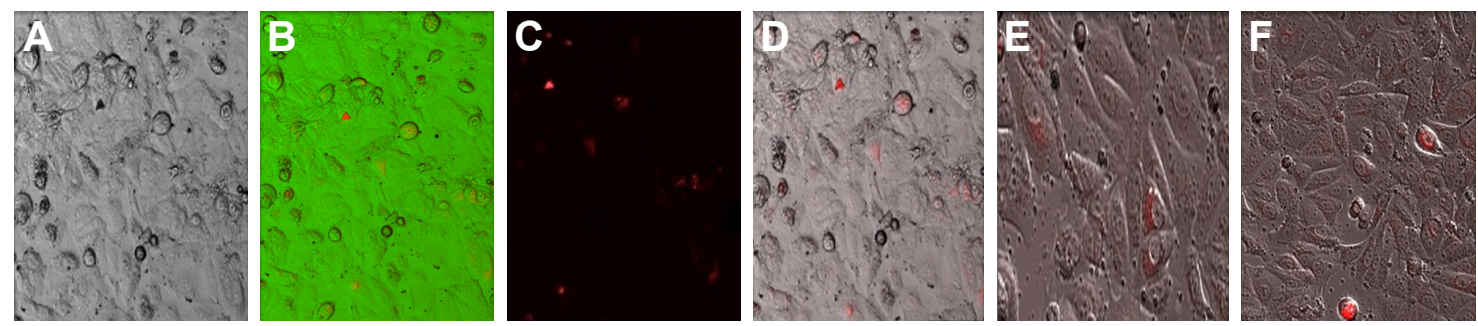

Figure 6 Light and fluorescence microscopy images of quantum dot (QD) labeled InP:ZnS QD-NPs in the MCF-7 cells.

Notes: (A) Untreated control cells. (B-D) 20x images of the cells after incubation with InP:ZnS QD-NPs for 4 hours. (E, F) Higher magnification of treated cells $40 \times$. Abbreviation: NPs, nanoparticles. 

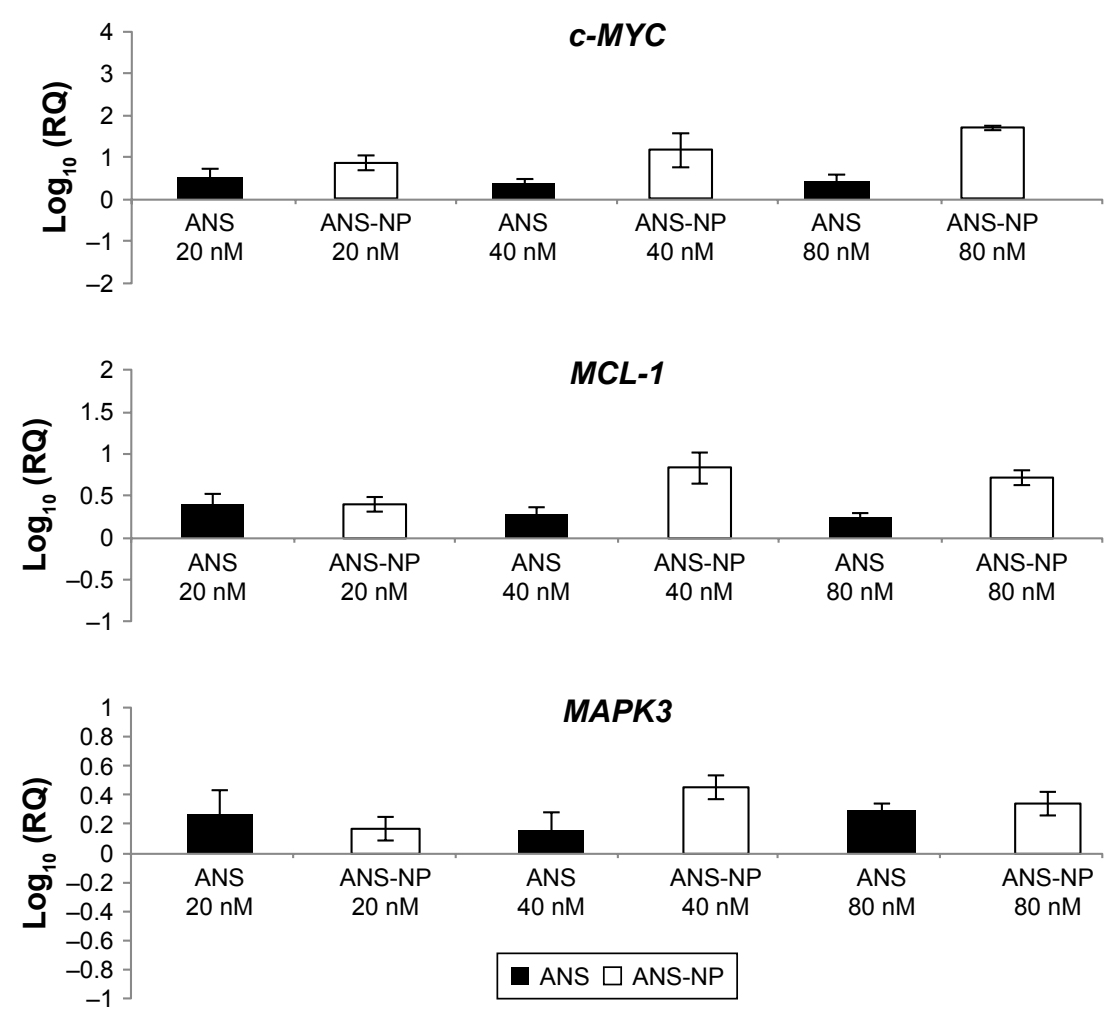

Figure 7 Gene expression of c-MYC, MAPK3, and MCL-I in MCF-7 cell lines treated with ANS and ANS-NPs for 96 hours.

Notes: The results showed upregulation of all the genes as response to ANS and ANS-NP treatments. Error bars represent standard error of the mean ( $n=3$ ).

Abbreviations: ANS, anastrozole; NP, nanoparticle.

if higher concentrations of the free drug are used. Moreover, drug-release profile of ANS-NP showed sustained release over 144 hours and did not exhibit burst effect in the first few hours. This prolonged release can be explained by the binding affinity between the polymer and the drug, and the capacity of the polymer to incorporate the drug. Previous studies have demonstrated that hydrophobic drugs have the tendency to have a lower release rate compared to hydrophilic ones. ANS is a water insoluble drug and prefers to stay within the hydrophobic core of the NPs ${ }^{24}$ thus the obtained results of prolonged release make these ANS-NPs candidates for sustained release therapy.

The result of the cytotoxicity study demonstrated the ability of ANS to enter the cell and exert its effect, as ANS-NP promoted a similar cytotoxic effect on cells as the free drug. This was also confirmed by observing the morphological changes in response to free ANS compared to ANS-NPs. Cellular uptake was further confirmed by the entry of the fluorescent InP:ZnS QD-NPs into the cytoplasm of MCF-7 cells. Moreover in this experiment, the efficacy of the NPs to deliver ANS was evaluated by real-time PCR and the gene expression behaviors of the $c-M Y C, M A P K 3$ (ERK1), and $M C L-1$ genes in the MCF-7 cells were compared. These genes were chosen as previous studies have demonstrated that ANS had an effect on the expression of these apoptotic genes, ${ }^{25}$ therefore the expression pattern between cells treated with free ANS versus ANS-NPs can be determined. The results showed that all three genes were overexpressed and that there was a similar expression pattern between ANS-NP and free drug treated cells, confirming the cytotoxicity experiments and proving the ability of the ANS-NPs to successfully deliver the drug into cells. MAPK3, also known as ERK1, is a member of the mitogen-activated kinase family, which is a fundamental component of the cellular signaling network that allows cells to function as a vital part of an organism..$^{26}$

All eukaryotic cells possess multiple MAPK pathways, which coordinately regulate gene expression, mitosis, metabolism, motility, survival, and differentiation. ${ }^{26}$ Surprisingly, a growing number of studies have suggested that in certain conditions, aberrant MAPK3 activation can promote cell death. Early reports of a proapoptotic function for the Ras/Raf/MAPK3 pathway appeared in 1996 after treating MCF-7 cells with Taxol. ${ }^{27}$ MAPK3 can trigger cell death by different mechanisms, including the activation of a CASP8 signaling cascade or by $p 53$ upregulation associated via $p 53$ phosphorylation on serine $15.28,29$

c-MYC protein is a transcription factor that plays multiple roles in breast cancer development and progression. c-MYC is 
a key regulator of cell cycle progression, cell proliferation, and transformation. ${ }^{30}$ However, when survival factors are deficient, c-MYC induces apoptosis by activating both mitochondrial and receptor-mediated apoptosis pathways. ${ }^{31}$ $c-M Y C$, which is stabilized by $M A P K$ via phosphorylation at serine 62 , increases the proapoptotic functions of $p 53 .{ }^{32}$ Interestingly, when combined with $c-M Y C$ overexpression, the constitutive activation of $M A P K$ is sufficient to induce apoptosis in Rat- 1 cells. ${ }^{33}$

Moreover, the upregulated expression of $M C L-1$, an antiapoptotic member of the $B C L-2$ family of proteins, observed in this study can be explained as an adaptive trait acquired by some tumors to offset $c-M Y C$-induced apoptosis. Alternatively, unknown anti-apoptotic events may presumably fulfill a similar role in transgenic tumors that do not overexpress MCL- $1 .{ }^{34}$ The real-time PCR results of this study indicated the ability of ANS-NPs to deliver ANS into the cells and to promote a similar and/or enhanced effect compared to that of free ANS, even at the molecular level.

\section{Conclusion}

In this study, amphiphilic PEG-PLA polymer was utilized to prepare ANS-NPs via the double emulsion method; the NPs had a mean diameter of approximately $186 \mathrm{~nm}$, a very narrow size distribution, and an EE of $67 \%$ and prolonged sustained release for 144 hours. ANS-NPs presented successful delivery of the drug, which was confirmed by in vitro cytotoxicity studies and by analyzing the differences in the expression of $M A P K 3, c-M Y C$, and $M C L-1$ in $M C F-7$ cells treated with free ANS and with ANS-NPs. These results demonstrated parallel expression patterns and a similar drug-induced response for both treatments representing a feature that can be utilized further for sitespecific tumor targeting.

\section{Acknowledgment}

This work was funded by the ministry of national guard health affairs (MNGHA), King Abdullah International Medical Research Center (KAIMRC) through grant RC 12/10, which is gratefully acknowledged.

We would like to acknowledge Dr Ahmad Alaskar, the executive director of KAIMRC, for his continuous support of this project. We would also like to thank the Research Center of the Female Scientific and Medical Colleges in King Saud University for supporting the study. The authors would like to thank Dr Rizwan Ali, from KAIMRC core facility for the confocal images.

\section{Disclosure}

The authors report no conflicts of interest in this work.

\section{References}

1. Hanahan D, Weinberg RA. Hallmarks of cancer: the next generation. Cell. 2011;144(5):646-674.

2. Płonka J, Latocha M, Kuśmierz D, Zielińska A. Expression of proapoptotic BAX and TP53 genes and antiapoptotic BCL-2 gene in MCF-7 and T-47D tumour cell cultures of the mammary gland after a photodynamic therapy with photolon. Adv Clin Exp Med. 2015;24(1):37-46.

3. Edson L, Hunter D, Coleman W. Alteration of pro-apoptotic and antiapoptotic gene expression in breast cancer cell lines (1047.7). FASEB J. 2014;28(1 Supplement).

4. Milani M, Jha G, Potter DA. Anastrozole use in early stage breast cancer of post-menopausal women. Clin Med Ther. 2009;1:141-156.

5. Miller WR, Larionov AA. Understanding the mechanisms of aromatase inhibitor resistance. Breast Cancer Res. 2012;14(1):201.

6. Buzdar AU. Anastrozole (Arimidex ${ }^{\mathrm{TM}}$ ) - an aromatase inhibitor for the adjuvant setting? Br J Cancer. 2001;85 Suppl 2:6-10.

7. Shavi GV, Nayak UY, Maliyakkal N, et al. Nanomedicine of anastrozole for breast cancer: physicochemical evaluation, in vitro cytotoxicity on BT-549 and MCF-7 cell lines and preclinical study on rat model. Life Sci. 2015;141:143-155.

8. Ediriwickrema A, Saltzman WM. Nanotherapy for cancer: targeting and multifunctionality in the future of cancer therapies. ACS Biomater Sci Eng. 2015;1(2):64-78.

9. Dong X, Mumper RJ. Nanomedicinal strategies to treat multidrugresistant tumors: current progress. Nanomedicine (Lond). 2010;5(4): 597-615.

10. Zidan AS, Sammour OA, Hammad MA, Megrab NA, Hussain MD, Khan MA, Habib MJ. Formulation of anastrozole microparticles as biodegradable anticancer drug carriers. AAPS PharmSciTech. 2006; 7(3):61.

11. Sarkar K, Yang H. Encapsulation and extended release of anti-cancer anastrozole by stealth nanoparticles. Drug Deliv. 2008;15(5):343-346.

12. Kumar A, Sawant KK. Application of multiple regression analysis in optimization of anastrozole-loaded PLGA nanoparticles. J Microencapsul. 2014;31(2):105-114.

13. Cheng J, Teply BA, Sherifi I, et al. Formulation of functionalized PLGAPEG nanoparticles for in vivo targeted drug delivery. Biomaterials 2007;28(5):869-876.

14. Whitehead KA, Langer R, Anderson DG. Knocking down barriers: advances in siRNA delivery. Nat Rev Drug Discov. 2009;8(2): $129-138$.

15. Wang Q, Bao Y, Ahire J, Chao Y. Co-encapsulation of Biodegradable Nanoparticles with Silicon Quantum Dots and Quercetin for Monitored Delivery. Adv Healthc Mater. 2013;2(3):459-466.

16. Massadeh S, Alaamery M, Al-Qatanani S, Alarifi S, Bawazeer S, Alyafee Y. Synthesis of protein-coated biocompatible methotrexateloaded PLA-PEG-PLA nanoparticles for breast cancer treatment. Nano Rev. 2016;7:10.3402/nano.v7.31996.

17. Dukes M, Edwards PN, Large M, Smith IK, Boyle T. The preclinical pharmacology of "Arimidex" (anastrozole; ZD1033) - a potent, selective aromatase inhibitor. J Steroid Biochem Mol Biol. 1996;58(4): 439-445.

18. Danhier F, Feron O, Preat V. To exploit the tumor microenvironment: passive and active tumor targeting of nanocarriers for anti-cancer drug delivery. J Control Release. 2010;148(2):135-146.

19. Forouzanfar MH, Foreman KJ, Delossantos AM, Lozano R, Lopez AD, Murray CJ, Naghavi M. Breast and cervical cancer in 187 countries between 1980 and 2010: a systematic analysis. Lancet. 2011;378(9801): 1461-1484.

20. Harvey JM, Clark GM, Osborne CK, Allred DC. Estrogen receptor status by immunohistochemistry is superior to the ligand-binding assay for predicting response to adjuvant endocrine therapy in breast cancer. J Clin Oncol. 1999;17(5):1474-1481. 
21. Jiang Q, Zheng S, Wang G. Development of new estrogen receptortargeting therapeutic agents for tamoxifen-resistant breast cancer. Future Med Chem. 2013;5(9):1023-1035.

22. Xiao RZ, Zeng ZW, Zhou GL, Wang JJ, Li FZ, Wang AM. Recent advances in PEG-PLA block copolymer nanoparticles. Int $J$ Nanomedicine. 2010;5:1057-1065.

23. Fang J, Sawa T, Maeda H. Factors and mechanism of "EPR" effect and the enhanced antitumor effects of macromolecular drugs including SMANCS. Adv Exp Med Biol. 2003;519:29-49.

24. Kemala T, Budianto E, Soegiyono B. Preparation and characterization of microspheres based on blend of poly(lactic acid) and poly( $\varepsilon$ caprolactone) with poly(vinyl alcohol) as emulsifier. Arabian Journal of Chemistry. 2012;5(1):103-108.

25. Itoh T, Karlsberg K, Kijima I, Yuan YC, Smith D, Ye J, Chen S. Letrozole-, anastrozole-, and tamoxifen-responsive genes in MCF-7aro cells: a microarray approach. Mol Cancer Res. 2005;3(4):203-218.

26. Murphy LO, Blenis J. MAPK signal specificity: the right place at the right time. Trends Biochem Sci. 2006;31(5):268-275.

27. Blagosklonny MV, Schulte T, Nguyen P, Trepel J, Neckers LM. Taxol-induced apoptosis and phosphorylation of Bcl-2 protein involves c-Raf-1 and represents a novel c-Raf-1 signal transduction pathway. Cancer Res. 1996;56(8):1851-1854.
28. Persons DL, Yazlovitskaya EM, Pelling JC. Effect of extracellular signal-regulated kinase on p53 accumulation in response to cisplatin. J Biol Chem. 2000;275(46):35778-35785.

29. Liu J, Mao W, Ding B, Liang C. ERKs/p53 signal transduction pathway is involved in doxorubicin-induced apoptosis in $\mathrm{H} 9 \mathrm{c} 2$ cells and cardiomyocytes. Am J Physiol Heart Circ Physiol. 2008;295(5): H1956-H1965.

30. Meyer N, Penn LZ. Reflecting on 25 years with MYC. Nat Rev Cancer. 2008;8(12):976-990.

31. Shi Y, Glynn J, Guilbert L, Cotter T, Bissonnette R, Green D. Role for c-myc in activation-induced apoptotic cell death in T cell hybridomas. Science. 1992;257(5067):212-214.

32. Sears R, Nuckolls F, Haura E, Taya Y, Tamai K, Nevins JR. Multiple Ras-dependent phosphorylation pathways regulate Myc protein stability. Genes Dev. 2000;14(19):2501-2514.

33. Kauffmann-Zeh A, Rodriguez-Viciana P, Ulrich E, Gilbert C, Coffer P, Downward J, Evan G. Suppression of c-Myc-induced apoptosis by Ras signalling through PI(3)K and PKB. Nature. 1997;385(6616): 544-548.

34. Allen TD, Zhu CQ, Jones KD, Yanagawa N, Tsao MS, Bishop JM. Interaction between MYC and MCL1 in the genesis and outcome of non-small cell lung cancer. Cancer Res. 2011;71(6):2212-2221.
International Journal of Nanomedicine

\section{Publish your work in this journal}

The International Journal of Nanomedicine is an international, peerreviewed journal focusing on the application of nanotechnology in diagnostics, therapeutics, and drug delivery systems throughout the biomedical field. This journal is indexed on PubMed Central, MedLine, CAS, SciSearch $®$, Current Contents ${ }^{\circledR} /$ Clinical Medicine,

\section{Dovepress}

Journal Citation Reports/Science Edition, EMBase, Scopus and the Elsevier Bibliographic databases. The manuscript management system is completely online and includes a very quick and fair peer-review system, which is all easy to use. Visit http://www.dovepress.com/ testimonials.php to read real quotes from published authors. 